\title{
Entrevista com a Prof. Dra. Leonor Scliar-Cabral, professora emérita da Universidade Federal de Santa Catarina (UFSC)
}

Realizada por Marcus MAIA ${ }^{1}$ e Eloisa PILATI² em 15 de novembro de 2018, em Natal, durante o VIII Seminário de Educação e Leitura.

\footnotetext{
${ }^{1}$ Universidade Federal do Rio de Janeiro (UFRJ) | Conselho Nacional de Desenvolvimento Científico e Tecnológico (CNPq), maiamarcus@gmail.com,orcid.org/oooo-0002-1583-3334. ${ }^{2}$ Universidade de Brasília (UnB) | Conselho Nacional de Desenvolvimento Científico e Tecnológico (CNPq), eloisapilati@gmail.com, orcid.org/oooo-ooo3-2895-5557.
} 


\section{Professora Leonor, a senhora poderia nos contar um pouco sobre sua trajetória na linguística, na psicolinguística e, especialmente, sobre o seu interesse por essa interface com a educação.}

Em primeiro lugar, gostaria de dizer que vou fazer 90 anos, e que me situo na segunda geração dos linguistas brasileiros. A primeira começa com o nosso Mattoso Câmara, de quem fui aluna em três cursos. O primeiro curso aconteceu no México, no segundo Instituto Linguístico da Associação de Linguística e Filologia da América Latina (ALFAL), o segundo ocorreu na PUC do Rio Grande do Sul e o terceiro, no Museu Nacional de Antropologia.

Minha trajetória na linguística começa na década de 60: eu estava cursando bacharelado em Ciências Jurídicas e Sociais e, em vez de me interessar mais pelas disciplinas do Direito, eu estava interessada na linguagem. Nessa época, eu já era professora e estava dando aulas particulares de Português e Latim. Eu queria conhecer mais, então, houve três obras que foram o início dessa minha formação, vamos dizer assim. Uma delas é uma obra do André Martinet, Elementos de Linguística Geral; as outras duas são A Linguagem e o Pensamento de Chauchard e Pensamento e Linguagem, de Vygotsky.

O que mais me chamou atenção na obra de Martinet foi a questão da dupla articulação da linguagem (a primeira, articula as unidades mínimas de significação, os monemas, enquanto a segunda, as unidades mínimas sem significado, os fonemas). À época, ele não tinha aplicado ainda a terceira articulação, que é a articulação dos traços, que, por sinal, não é uma articulação sequencial, é uma articulação simultânea. Em decorrência dessa simultaneidade, não há linearidade na articulação dos traços fonéticos. 
Voltando à temática da dupla articulação, a morfologia é a disciplina que se ocupa das unidades mínimas dotadas de significado, que Martinet denominou de monemas, enquanto a fonologia se ocupa das unidades mínimas destituídas de significado. Penso que o princípio, em essência, da articulação é válido até hoje. Por quê? Porque exatamente o que diferencia a estrutura e o funcionamento das línguas é o princípio de que nós temos níveis e que (agora eu vou acrescentar o que hoje eu acho essencial, inclusive, do ponto de vista da psicolinguística e da neurociência), quanto mais baixo o nível, mais ele tem de ser automatizado para as articulações dos níveis superiores, que são em aberto e são níveis que operam com elementos mais abstratos. À medida que os níveis vão subindo mais abstratos eles se tornam, mais complexos e permitem maior criatividade. Nos níveis mais baixos, vige o princípio do paradigma fechado, ali não se exerce a criatividade. Não é possível entrar com um novo traço invariante para distinguir os fonemas da Língua Portuguesa, certo? Quanto mais baixo o nível, tanto mais os elementos mínimos têm de ser automatizados e por isso é que são tão poucos. Então, há uma coerência entre a necessidade da automatização com o número menor de elementos que constituem o paradigma e tanto mais eles são condicionados pelo nível que vem a seguir. Então, são regras. Esse princípio da articulação, que Martinet chamava de dupla articulação, eu ampliei depois com todos esses conceitos que acabei de emitir e que são enriquecimentos: veja que já entrei com o princípio da criatividade e onde ela interfere.

Por exemplo, vamos partir da produção e não da percepção. A produção, em termos de processamento, começa nos níveis mais altos, mais complexos, mais criativos e mais abstratos. Você tem que partir da Mensagem, definida por Levelt como o nível que resume o conteúdotextualmaisamploe, ao mesmotempo, maisesquematizado do que você quer comunicar. Já mencionei que o nível mais alto vai condicionar o nível imediatamente abaixo, portanto, vai condicionar 
a lexicalização, porque, de acordo com aquilo que você se propõe dizer, é que você vai escolher os itens lexicais da memória semântica, vai selecionar as significações básicas e, assim, sucessivamente.

\section{Como se daria a relação entre fonologia, morfologia com a sintaxe, sob essa perspectiva?}

Essa relação só se dá depois de você escolher os itens lexicais, embora quando você agrega os morfemas puramente gramaticais, eles já contenham a informação sintática, mas a informação sintática não depende só dos traços gramaticais inerentes. Ela vai depender também, obviamente, do relacionamento que se estabelece entre os itens. Quando você escolhe o item lexical, você escolhe a face do significante, também. Ao escolhê-lo, já condiciona quais os fonemas que o compõem, você não tem liberdade de escolha: uma vez selecionada uma palavra, você não tem mais liberdade de escolher quais são os fonemas que vão entrar nela, nem tem liberdade para articulá-los de outra forma.

Então, você está notando que a cada nível mais baixo, você vai condicionando mais o que vem a seguir. É claro que aqui entram em jogo também (é bem complexo isso) as regras morfofonêmicas, inclusive a questão do sândi. Por exemplo, na palavra "inimigo", no momento em quevocê escolhe o prefixo "in-" e o radical "amig-", o " $a$ "vai se transformar em "i", a nasalidade do prefixo vai se transformar numa consoante nasal que adere à primeira vogal do radical, formando a sílaba "ni" eavogaldoprefixo desnasaliza:vocêdesmanchouoprefixo, que agora é o alomorfe "i-“. Então, nós temos que levar em conta que há todas essas regras, mas elas se aplicam automaticamente, você não tem liberdade para optar por "não, não vou fazer isso". Em suma, os traços fonéticos são totalmente condicionados. Na percepção é 
o inverso, você começa pelo nível mais baixo, mais condicionado e automático, e vai subindo até os níveis mais abstratos, onde reina a criatividade.

Conforme já referido, as outras obras que foram fulcrais, nesse período inicial de minha formação, foram A Linguagem e o Pensamento de Chauchard e Pensamento e Linguagem, de Vygotsky. Na década de 6o, eu já tinha lido essas obras. Quando eu as li, senti a necessidade de compreender como o cérebro funciona e formei um grupo para tomar aulas com o maior neurologista de Porto Alegre, de então, Dr. Job. Comecei a estudar como o cérebro funciona em relação à linguagem na década de 60.

\section{A década do cérebro vem a ser a década de 90. Considerando esse fato, é possível dizer que a senhora foi uma precursora desse movimento que pretende investigar as relações do cérebro com a aprendizagem e com a educação. 0 que mais gostaria de nos dizer sobre a temática da educação e das ciências cognitivas?}

A preocupação com a educação está presente desde o início dessas minhas indagações, já quando eu estava cursando o curso de Letras na PUC do Rio grande do Sul. Por exemplo, ainda como aluna da graduação, eu fui chamada a dar aulas para a formação de professores de Português. Sou fundadora da pós-graduação em Linguística da PUC do Rio Grande do Sul que começou em 1970 como resultado do seminário que eu proferi em 1969. Quando eu dava aula na graduação, coordenei uma pesquisa dos alunos sobre as entradas dos empréstimos linguísticos, para verificar como ocorre a mudança de 
campo semântico usando radicais já existentes da língua. Estavam começando os voos espaciais, então, foi feito um levantamento sobre todo o léxico novo e as formas que foram empregadas para registro das novas experiências. Também fizemos pesquisas para ver como as contribuições da linguística poderiam influir na melhoria do ensino em sala de aula, isso na década de 60.

\section{Sabemos que a educação básica no} Brasil enfrenta diversos problemas. Há indicadores que nos mostram que há crianças ficam mais de 10 anos na escola e saem incapazes de articular suas ideias com a clareza e coerência necessárias, sem falar no alto nível de analfabetismo funcional. Qual a sua opinião sobre essas questões? Como chegamos a uma situação dessas? 0 que podemos fazer para renovar a educação brasileira?

A situação é gravíssima: o último levantamento do INAF, 2018 (Indicador de Alfabetismo Funcional) mostra que houve uma regressão no que se considera o alfabetismo pleno. Nós estamos apenas com $12 \%$ da população que podemos assegurar que realmente compreende os textos que circulam socialmente. O que nós podemos entender disso? Não pode existir cidadania se as pessoas não puderem se formar, assumindo um posicionamento crítico: mas, primeiro, elas têm que saber ler, têm que compreender o que leem, não é? Como é que você vai assumir posição crítica se você não compreende o texto? Sem isso não há exercício da cidadania e os resultados nós estamos verificando, estamos sofrendo na própria carne. 
Bem, mas por que tudo isso? Por que a educação é de tão baixa qualidade no Brasil? Eu interpreto da seguinte maneira: a partir de um fator muito bom que foi abrir a escola, principalmente, o Ensino Fundamental, que passou a ser obrigatório nos seus primeiros anos, se não os pais sofrem sanções. Isso foi uma medida muito saudável, abrir a escola para todos, porém essas medidas não podem ser populistas, sabe? Tal medida tem de obedecer a um planejamento e a falha foi que careceu da proatividade. Ou seja, não houve o cuidado fundamental, que seria a preparação dos professores para atender a demanda. Foram admitidos no Ensino Fundamental, sem menosprezar qualquer pessoa, sem nenhuma formação específica: o alfabetizador precisa deuma formação muito específica, muito sólida, muito bem fundamentada. Não podemos continuar negligenciando a formação específica do alfabetizador. Infelizmente não se trata só do alfabetizador, mas também dos mentores da alfabetização, para as BNCC (Base Nacional Comum Curricular). Eles ainda acham que o Português só tem cinco vogais: $a, e ́, i, o ́, u$. Como é que você vai alfabetizar uma criança se você pensa que a Língua Portuguesa só tem cinco vogais orais? Certo? Então o que aconteceu? Houve um nivelamento por baixo. Cada vez ele vem aumentando mais. Por exemplo, as políticas das cotas são uma medida excelente, mas volto à crítica de que não pode ser uma medida populista. Ela tem de ser acompanhada por um trabalho dirigido para essa população, para preencher os pré-requisitos que ela necessita para poder acompanhar os cursos nos quais ela foi admitida. Então todas essas medidas populistas acabaram tendo como resultado um nivelamento por baixo: a qualidade da educação foi baixando progressivamente, porque, como eu disse, houve uma regressão, o número de indivíduos aptos a lerem e compreenderem baixou, está em $12 \%$, se você comparar com o levantamento que o INEP fez em 2009. 


\section{Qual a importância e qual a influência da ampliação do acesso ao ensino superior público na formação de professores?}

Nós voltamos ao mesmo princípio da educação básica mencionado anteriormente. Universidade é muito mais do que levantar prédios e abrir salas de aula. $\mathrm{O}$ fulcro da aprendizagem acadêmica está na formação do professor, correto? Então a causa está aí. Faltou acrescer uma outra causa, que são os fundamentos das políticas públicas de educação, em particular, da alfabetização, dos anos iniciais, que agora foram reduzidos a dois, o ciclo da alfabetização. Todas as bases estão furadas. Vimos, por exemplo, ontem, no VIII Seminário de Educação e Leitura, que nas avaliações nacionais não sabem nem formular uma comanda, não sabem nem formular um princípio. O que seria, entre aspas, um fundamento? Porque de fundamento aquilo não tem nada. Falta coerência até na formulação. Por exemplo, um fundamento essencial à alfabetização é que, para você passar do sistema oral para o sistema escrito, nós temos descontinuidades, pois, começa que o sistema oral é adquirido e o sistema escrito é aprendido.

A BNCC apresenta o seguinte texto inicial: "Na continuidade do sistema oral para o sistema escrito". Aqui está o fundamento básico que mostra o fracasso da alfabetização, pois as políticas públicas de alfabetização apresentam problemas sob o ponto de vista epistemológico, principalmente, nem sabem a diferença entre recepção e produção, para elas isso não existe, escrita e leitura são a mesma coisa.

Vocês perguntaram por que a qualidade da educação está tão baixa. Uma terceira causa é porque as pessoas repetem, como papagaios, sem até entender, é claro, por exemplo, a expressão “epistemologia genética", que nos deu grandes contribuições, mas não entendem e ficam repetindo e dizendo que não é preciso método, porque a criança por si só vai aprender os princípios da alfabetização. 
Algo que só foi inventado tardiamente, certo? Só há 5 mil anos atrás surgiram os primeiros sistemas de escrita, uma construção lenta e coletiva e os sistemas alfabéticos ainda muito mais tarde; e uma criança vai entrar na escola e já vai poder escrever seu nome? Caramba! Ela está desenhando seu nome, ela não está escrevendo coisa nenhuma. Desenhoé um sistema diferente da linguagem verbal.

\section{Quais são as principais diferenças entre sistema oral e sistema escrito?}

A primeira grande descontinuidade foi aquela já colocada: a criança quandovem a escolajátem conhecimento para o uso da suagramática, não precisa ninguém ensinar para ela que o artigo, o determinante, vai na frente do substantivo, ela nem tem consciência disso. Ela vai precisar ter consciência disso para escrever. Aí ela vai precisar ter um conhecimento não só para o uso, mas um conhecimento metalinguístico, que é o ensino da gramática, certo? Metalinguagem é sinônimo de conhecimento consciente da gramática, mas conhecimento para o uso ela já tem.

Primeira descontinuidade: Para aprender a ler e a escrever não basta o conhecimento para o uso que a criança já tem, porque ela vai ter de realizar uma desconstrução. Exatamente. É isso, ela vai ter que desconstruir como ela percebe a linguagem oral. Por exemplo, a percepção, no primeiro nível, não é uma percepção, por exemplo, da segunda articulação da linguagem. Ela percebe por unidades silábicas, ela não percebe no primeiro momento que a sílaba é constituída por unidades menores. Então, isso vai ter que ser desconstruído. A coisa mais difícil, de uma complexidade enorme, é você desconstruir uma coisa que você sempre percebeu como uma unidade indissolúvel. 
Então, essa é a grande desconstrução, a desconstrução de que agora você vai ter que trabalhar com a linguagem verbal de forma consciente. Outra desconstrução, essa eu aprendi só recentemente, graças à neurociência, e já estou aplicando esse princípio sistematicamente à alfabetização, já vou explicar. A segunda desconstrução vai ser trabalhada primeiro, porque nós começamos pela leitura, mas primeiro você tem que aprender a automatizar o reconhecimento de quais, quantos e como se combinam os traços das letras. Começa por aí. De qual desconstrução se trata? É que os neurônios da visão não reconhecem e não operam com traços importantes para o reconhecimento das letras, os traços da direção, princípio com o qual Dehaene trabalha muito.

Na verdade, os neurônios da visão não reconhecem nem operam não só com o traço da direção, mas também não reconhecem outros traços mínimos e delicadíssimos, necessários para identificar uma letra como sendo diferente da outra. Os neurônios da visão foram biopsicologicamente programados para reconhecer as entidades por configuração, os limites, os contornos, as invariâncias desses contornos, por exemplo: vocês estão vendo aqui à minha frente essas poltronas; vejam que na fileira lá do fundo vocês vão reconhecer que são as mesmas cadeiras, apesar de estarem vendo só um terço. É por configuração, mas para reconhecer as letras isso vai ter que ser desconstruído e deve ser aprendido de forma sistemática a perceber a direção para direita e para esquerda.

Como se dá essa aprendizagem? Cada uma das letras que são introduzidas obedece os seguintes passos: automatizar o reconhecimento dos traços das letras, automatizar o valor que o grafema tem e automatizar como é que você reconhece onde cai a intensidade no vocábulo. Isso é trabalhado sistematicamente. De que forma? Suponhamos que seja a primeira letra, $\mathbf{b}$, da palavra-chave "bola" (em letra de imprensa, numa folha distribuída aos alunos). 
É dado o seguinte comando à criança: "Com o dedo indicador, de cima para baixo trace a reta" (a criança está identificando qual é o traço e qual a direção); "no meio da reta, à direita do traço, trace um semicírculo, começando da esquerda para a direita e concluindo na base, da direita para a esquerda" (a criança está identificando qual é o traço, qual a direção e como se combina com o primeiro).

Está bem explicado como ensinamos a criança a desconstruir sua percepção visual inata? $\mathrm{E}$ assim nós fazemos com todas as letras. Como o grafema $<\mathbf{b}>$ representa o fonema oclusivo $/ \mathbf{b} /$, não dá para pedir para a criança emitir o som que realiza o fonema. Por isso, nós só introduzimos os grafemas que representam os fonemas oclusivos, a partir da Unidade 11, porque aqui nós temos que trabalhar com sílabas, na emissão.

A primeira aplicação do fundamento da descontinuidade na passagem do sistema oral para o escrito é a desconstrução da simetrização dos neurônios da visão, certo? A aprendizagem da dessimetrização pelos neurônios da visão vai continuar convivendo simultaneamente com a simetrização inata. A outra desconstrução é desmanchar a sílaba, certo? Isso é uma descontinuidade. Vai de encontro a como nós percebemos a fala, inatamente.

\section{Qual a relação entre alfabetização e a expressão "reciclagem neuronal"?}

A reciclagem neuronal é uma metáfora de como você vai escolher, dentre os parâmetros disponibilizados, aqueles que possibilitarão a especialização para determinadas tarefas e, ao mesmo tempo, inibir os parâmetros que não lhes são úteis. 


\section{Como fazer com que todos esses avanços das ciências que se ocupam da linguagem e aqui, especificamente, da linguística se apliquem ao ensino em sala de aula, no caso, ao ensino da Língua Portuguesa?}

Eu vejo essa questão sob dois aspectos. Em primeiro lugar, no ensino-aprendizagem existe resistência a tudo aquilo que vem de encontro a mitos arraigados e você tem uma grande dificuldade em fazer com que o professor se desprenda daqueles mitos; como, por exemplo, alguns mitos bem recentes. Um mito, por exemplo, é que, reconhecendo de que gênero se trata, você já vai saber ler e escrever. Esse mito não é só dos professores, desafortunadamente, é de muitos colegas nossos da linguística. Nós temos aquele outro mito de que a criança está alfabetizada quando decora o alfabeto.

Então a coisa mais difícil é você romper um mito e fazer com que as pessoas pensem com suas próprias cabeças, elaborem suas próprias hipóteses. Desafortunadamente, na academia, nós ainda falamos muito para nós próprios. Os nossos colegas (eu às vezes até ainda sofro desse mal) estão mais preocupados em publicar os artigos em um periódico bem indexado do que dialogar com os professores em sala de aula. Às vezes, escuto a acusação de "Ah, mas como? Tu, ao invés de estares trabalhando no desenvolvimento da teoria, estás te preocupando em formar professores e alfabetizadores". Estão achando que eu não estou fazendo linguística.

Agora vamos precisar mais a resposta à pergunta: como aplicar esses avanços da teoria linguística à produção textual nos níveis mais altos? Eu vou lhe dar um exemplo que é fatal, nós não usamos a vírgula seguindo a nossa intuição, não é seguir aquele conselho do professor: "Quando fizer uma paradinha, taca uma vírgula”, conhece essa frasezinha? 
Não é assim que nós vamos ensinar a usar a vírgula: nós só podemos colocar esse importantíssimo auxiliar para compreender o texto, que é a vírgula, se nós soubermos sintaxe. Nós temos de saber que, apesar daquela pausa, aquela paradinha maior entre sujeito e predicado, não há vírgula. Por que existe uma pausa maior? Porque o predicado contém a informação nova e o sujeito, a conhecida, então, para processar o que já sabemos, o custo de processamento é menor; agora, para organizar a informação nova que está contida na frase verbal, predicado, o custo é muito mais complexo, por isso, nós fazemos uma pausa para organizar as ideias, então, colocar uma vírgula ali ocasiona o erro mais fatal, separar o sujeito do predicado.

Nós temos que ensinar sintaxe, agora é claro que nós não vamos ficar com o nosso aluno do Ensino Fundamental, do $9^{\circ}$ ano, só lhe ensinando a fazer arvorezinha, não é? Você tem é que realmente ensinar o que é a frase verbal e o que é a frase nominal, com várias estratégias, de modo que ele aprenda essa informação de modo consciente: para falar, ele já tem esse conhecimento intuitivo. Ele sabe para o uso o que é uma frase verbal e uma frase nominal, mas agora vamos ter que ensinar tais conhecimentos a nível consciente, certo? Outro nome para metalinguagem, conforme já afirmado, é gramática, gramática de forma consciente.

\section{A senhora está fazendo um trabalho lindo no que se refere ao desafio de tentar romper as barreiras da universidade e estabelecer um diálogo com a sociedade. Quando foi que a senhora resolveu dar esse passo em direção a um maior diálogo com as escolas da educação básica?}


Isso começou, como disse a vocês, na década de 60, nós íamos à escola e ministrávamos cursos de formação, o Irmão Elvo Clemente, já falecido, patrocinava cursos de formação de como ensinar a Língua Portuguesa, então, desde cedo eu fiz isso. Tenho procurado realizar um trabalho a nível municipal, chegar às secretarias municipais; às vezes, eu não consigo chegar nem as secretarias, porque ali já existe um núcleo duro que não permite as desconstruções dos mitos. Mas quero dizer que tenho conseguido vitórias extraordinárias, vamos falar agora mais recentemente, como em Sergipe e Alagoas: foram os dois estados que apresentaram os piores resultados em leitura $\mathrm{e}$ escrita, na avaliação da Ana de 2016 cujo resultados foram divulgados em 2017. O meu esforço está muito dirigido para trabalhar nas bases, no nordeste. Eu comecei a minha experiência em Lagarto, que fica perto de Aracaju, acho que é a terceira cidade mais importante, não é a capital. Ali nós começamos com um trabalho piloto, no qual conseguimos professoras que aceitaram o método. O que aconteceu lá? Em 2017, eu encontrei duas professoras magníficas, Patrícia e Jaqueline, uma delas com duas classes e a outra com uma classe, o público alvo foram 70 crianças.

Noprimeiro ano, a ênfase da alfabetizaçãoé para leitura, embora já trabalhemos a produção escrita com fichas com as letras, porque os esquemas motores para automatizar a escrita cursiva são muito mais complexos de aprender. Assim, os alunos já começam a produzir suas primeiras palavras e até pequenas frases com fichas móveis, sabe? É como se estivessem digitando. Com computador daria para iniciar esse processo, se as escolas públicas já tivessem os tablets.

Em Lagarto, começamos com essas duas professoras, em 2017. Veja que a gente foi para a base mesmo. O resultado foi espetacular, em escolas das periferias: alunos com sandália de dedos, alunos com marca de quem apanhou do pai, aluno com pai na prisão! Essas 70 crianças se tornaram verdadeiras leitoras, gostando de ler, devoram 
os livros da caixa com livros da sala de aula.E daí, com ôxito, a SEMED de Lagarto assumiu, em 2018, o Sistema Scliar de Alfabetização, para alfabetizar 365 crianças do $1^{\circ}$ ano e mais as $65 \mathrm{de} 2017$, agora no $2^{\circ}$ ano, para a alfabetização com ênfase na escrita, num total de 430 crianças. O êxito irradiou-se aos municípios vizinhos e agora estou atualmente com quatro SEMEDs que adotaram o Sistema: em Lagarto, SE; em São José da Laje, Alagoas; em Capinzal, Maranhão e em Tobias Barreto, $\mathrm{SE}$ as coisas estão mudando a partir das bases.

\section{Em relação ao Método Scliar, quais são os planos para o futuro}

O que vem mais já está acontecendo, porque eu fechei a elaboração do material do primeiro módulo, com ênfase na leitura. Agora estou terminando o segundo módulo, com ênfase na escrita. É sempre um tripé: os fundamentos, pois o professor tem que saber o que está no bojo de cada atividade, do que está obtendo com aquela atividade, quais são as dificuldades, enfim, é um livro de fundamentos que trabalha, inclusive, com as descontinuidades. Depois nós temos o livro da criança, Aventuras de Vivi (o do segundo módulo se chama Aventuras de Vivi no Mundo da Escrita), que é um livro de histórias, as crianças ficam encantadas; então, na página à esquerda, estão as letras e as palavras-chave e, à direita, está o capítulo de onde foram extraídas essas palavras. E aí, nós temos as palavras negritadas, que contêm as letras que as crianças já sabem ler, porque automatizaram o reconhecimento de quais, quantos e como se combinam os traços invariantes das letras, bem como os valores dos grafemas e as não negritadas. É feita uma leitura interativa, o professor lê o que não está negritado e as crianças, em coro, vão lendo o que está negritado.

Depois o professor faz a leitura completa com expressividade, colocando os padrões de entoação; em seguida, aplicam-se os 
exercícios de desenvolvimento da compreensão e da capacidade de referenciar. Quando as crianças chegam a dois terços do livro, quase todas as palavras já estão praticamente negritadas, as crianças já sabem ler tudo. Agora respondendo, o segundo módulo já está quase pronto. Ah, faltou mencionar o terceiro livro do tripé. São os Roteiros para o Professor (Módulos 1 e 2) para aplicação de cada unidade, onde são dadas as instruções de como o professor deve ditar as comandas, aquelas comandadas do tipo "Trace com o dedo para a esquerda, para direita", que não podem ser dadas de improviso, porque são muito complexas.

O professor lê aquele comando e fica observando se as crianças estão fazendo direitinho o traçado. Acompanha o livro de Anexos, cujas folhas são reproduzidas para as crianças desenvolverem as atividades, por exemplo, folhas com as letras em tamanho maior. No segundo Módulo, o fulcro é a alfabetização para a escrita, mas não descuidamos do desenvolvimento da competência leitora e ampliação sistemática, em cada unidade.

\section{Como citar}

MAIA, Marcus; PILATI, Eloisa. Entrevista com a Prof. Dra. Leonor Scliar-Cabral, professora emérita da Universidade Federal de Santa Catarina (UFSC). Revista da Abralin, v. 17, n. 1, p. 34-49, 2018. 